\title{
Characteristics and Outcome of Trauma Patients in a Mixed ICU: A Retrospective Review
}

\author{
Henry Y. Embu1 ${ }^{*}$, Samuel I. Nuhu1 ${ }^{1}$ Erdoo S. Isamade1, Daniel D. Kokong2, \\ Kenneth N. Ozoilo ${ }^{3}$, Daniel 0. Agbo ${ }^{1}$ \\ ${ }^{1}$ Department of Anaesthesia, Jos University Teaching Hospital, Jos, Nigeria \\ ${ }^{2}$ Department of Otorhinolaryngology, Jos University Teaching Hospital, Jos, Nigeria \\ ${ }^{3}$ Department of Surgery, Jos University Teaching Hospital, Jos, Nigeria \\ Email: "embuy@yahoo.com
}

Received 15 June 2016; accepted 25 July 2016; published 28 July 2016

Copyright (C) 2016 by authors and OALib.

This work is licensed under the Creative Commons Attribution International License (CC BY). http://creativecommons.org/licenses/by/4.0/ (c) (i) Open Access

\begin{abstract}
Background: Trauma is a major public health challenge in Nigeria and many victims of trauma are brought to the hospital critically ill, thereby increasing the burden of critical illness in the country. Aim: To characterize the pattern of injuries, causes and outcome among trauma patients admitted into the general ICU of a tertiary care hospital in north-central Nigeria. Materials and Methods: All trauma admissions into the ICU of Jos University Teaching Hospital over a 14-year period were retrospectively reviewed. Information obtained included the patients' demographics, diagnosis, aetiology, complications, interventions, outcome and length of stay in the ICU. Results: Trauma admission during the period was 396 which was $29.66 \%$ of total ICU admissions in the same period. The male:female ratio was 3:1 and the age range was 2 months to 75 years (median 25 years). $78.54 \%$ of trauma admissions were from the accident and emergency, $15.66 \%$ from the theatre and $5.80 \%$ from the ward. The most common cause of injury was burn $160(40.40 \%)$, followed by road traffic crashes $152(38.38 \%)$ and the least common cause of injury was gunshot $28(7.07 \%)$. Mortality rate among trauma patients was $48.74 \%$ while mortality in the ICU within the same period was $34.08 \%$. Burns accounted for $50.78 \%$ of deaths while head injury accounted for $33.68 \%$ of deaths. Mortality was higher in the age groups 16 - 30 years and greater than 45 years $(p=0.03)$. Conclusion: Trauma constitutes a significant cause of admission into our general ICU and mortality in these patients is higher than in the general population of ICU patients. Establishing trauma ICU would lead to streamlining of facilities which could improve outcome.
\end{abstract}

\section{Keywords}

Trauma Admissions, General ICU, Outcome

${ }^{*}$ Corresponding author.

How to cite this paper: Embu, H.Y., Nuhu, S.I., Isamade, E.S., Kokong, D.D., Ozoilo, K.N. and Agbo, D.O. (2016) Characteristics and Outcome of Trauma Patients in a Mixed ICU: A Retrospective Review. Open Access Library Journal, 3: e2819.

http://dx.doi.org/10.4236/oalib.1102819 


\section{Subject Areas: Emergency \& Critical Care}

\section{Introduction}

Trauma is a major public health challenge and a leading cause of deaths, morbidity and disability in Nigeria and most parts of the developing world. Motor vehicular crashes are a major cause of trauma in these countries. While developing countries are said to account for $48 \%$ of motorized vehicles, they account for $91 \%$ of fatalities due to road traffic crashes per annum [1]. It is estimated that if this trend is not reversed, trauma due to road traffic crashes is set to rank among the top three causes of Disability Adjusted Life Years (DALYS) lost in the next 15 years. Nigeria is said to have the third highest number of deaths yearly from road traffic accidents in the world and the highest in Africa [2]. However, Nigeria is also faced with other causes of injuries like armed conflicts that are prevalent in the north and petroleum pipeline explosions that keep recurring in the south.

Many of the victims of these road traffic crashes are brought to the hospital critically ill, thereby increasing the burden of critical illness in the country. This is despite other factors like urbanization, emerging epidemics and increasing access to hospitals which are also increasing the burden of critical illness in many developing countries [3]-[5]. Trauma centres and trauma intensive care are not common practice in Nigeria and critically ill trauma patients have to compete with other critically ill patients for intensive care beds in mixed ICUs. This is against the back drop of increasing mortalities of severely injured patients in the ICU [6] [7].

Although there are increasing attempts at trauma data keeping such as the Jos University Teaching Hospital trauma registry, it is necessary for centres that manage critically ill trauma patients to highlight their experiences. The primary objective of this study is to characterize the pattern of injuries, causes and outcome among trauma patients admitted into the general ICU of a tertiary care hospital in north-central Nigeria.

\section{Materials and Methods}

Approval for the study was obtained from the hospital ethics committee and all trauma admissions into the intensive care unit of Jos University Teaching Hospital from $1^{\text {st }}$ January, 1994 to $31^{\text {st }}$ December, 2007 i.e. over a 14 year period formed the population for this study. Jos is a city located in north-central Nigeria.

The hospital has a 500 bed capacity with a general intensive care unit that has six beds. The ICU admits patients from various specialties including medicine, surgery and obstetrics and gynaecology. It is managed by consultant anaesthetists, residents and doctors in the various specialties and manned by trained ICU nurses.

Data were obtained from the ICU records and patient case files. These were retrospectively reviewed. Information obtained included the patients' demographics, diagnosis, aetiology, complications, interventions, outcomes and length of stay in the ICU. Case files that were missing or without adequate records were not included in the study.

Data were analyzed using Epi info version 7 statistical package. The categorical data were presented as percentage while the continuous data were presented as mean and standard deviation. Student t-test was used to compare categorical data while Mann-Whitney test was used to compare continuous data. Statistical significance was defined as a p value $<0.05$.

\section{Results}

There were 1335 admissions in the ICU during the period of study out of which 422 were as a result of trauma but 396 of these had adequate records and were analyzed. This was $29.66 \%$ of the total ICU admissions. There were 297 (75\%) males and 99 (25\%) females with a male to female ratio of 3:1. The male to female ratio for the total ICU admissions during the same period was 1.1:1.The age range was from 2 months to 75 years with a mean age of $26.9 \pm 16.4$ years (median 25 years). Of the admissions 311 (78.54\%) were from accident and emergency while $62(15.66 \%)$ were from the theatre and 23(5.80\%) from the ward and 381 (96.20\%) of admissions were emergencies (Table 1 ).

The most common cause of injury was burn 160 (40.40\%) followed by road traffic accident (RTA) 152 (38.38\%) and the least common cause of injury was gunshot 28 (7.07\%) (Table 2). 83 (54.52\%) of the RTAs were motorcycle related while 69 (45.48\%) were due to motor vehicular crashes. 
Table 1. Demographic and clinical characteristics of ICU trauma admissions.

\begin{tabular}{lcc}
\multicolumn{1}{c}{ Variable } & Trauma admissions & Total admissions \\
\hline Number [n(\%)] & $396(29.66)$ & $1335(100)$ \\
Sex (male:female ratio) & $3: 1$ & $1.1: 1$ \\
Age (years) & & \\
$\quad$ mean/media & $26.9 \pm 16.4 / 25$ & $29 \pm 19.7 / 27$ \\
$\quad$ Modal & & \\
LOS in ICU [n(\%)] & $137(34.60)$ & $631(47.26)$ \\
$\quad<3$ days & $259(65.40)$ & $704(52.74)$ \\
$\geq 3$ days & & \\
Source of admission [n(\%)] & $311(78.54)$ & $418(31.28)$ \\
A \& E & $62(15.66)$ & $604(45.25)$ \\
Theatre & $23(5.80)$ & $283(21.22)$ \\
Wards & - & $30(2.25)$ \\
Other hospitals & $15(3.80)$ & $455(34.08)$ \\
Type of admission [n(\%)] & & \\
Emergency & & \\
Elective & & \\
Mortality (\%) & & \\
\hline
\end{tabular}

Keys: LOS = Length of stay; A \& E = Accident and Emergency.

Table 2. Causes of trauma.

\begin{tabular}{ccc}
\hline Cause of injury & Frequency & Percentage \\
\hline Burns & 160 & 40.40 \\
Road traffic accidents & 152 & 38.38 \\
Assaults \& Conflicts & 52 & 13.13 \\
Gunshots & 23 & 5.82 \\
Others & 9 & 2.27 \\
\hline
\end{tabular}

Figure 1 shows the causes of burn in the patients. Petroleum product explosions and scald were the most common causes of burn in 90 (56.25\%) and 33 (20.63\%) of patients respectively.

Isolated injuries occurred in 270 (68.18\%) patients while multiple injuries occurred in 126 (31.82\%) patients. The most common site of injury was the head and neck in $302(76.25 \%)$ followed by abdominal injuries in 107 (27.02\%) and musculoskeletal in 78 (19.70\%) patients (Table 3). The most common type of injury was soft tissue injuries followed by burn and craniocerebral injuries with 372 (93.93\%), 160 (40.40\%) and 121 (30.55\%) of patients affected respectively (Figure 2).

The length of stay (LOS) was from a few hours to 49 days with a medium LOS of 7 days. Sixty three (15.91\%) had a LOS of less than one day and 297 (75\%) of patients had a LOS of less than 7 days (Table 4).

Of the 396 patients admitted, 193 died giving a mortality rate of $48.74 \%$ while 203 (51.26\%) were transferred out of the ICU alive. Mortality rate in the ICU during the same period was $34.08 \%$. Of the deaths, $71.50 \%$ occurred in males but was not significantly different from the mortality in the female population. Burn contributed $50.78 \%$ of the deaths while head injury contributed $33.68 \%$. Mortality in the age ranges 16 - 30 years and greater 


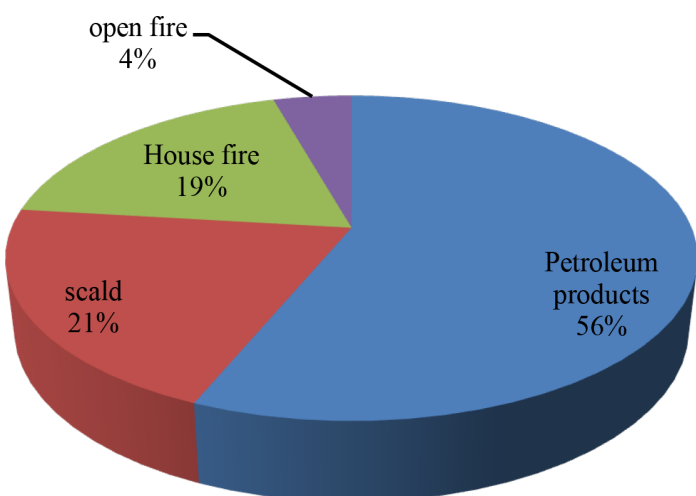

Figure 1. Causes of burn.

Table 3. Sites of injury.

\begin{tabular}{ccc}
\hline Site of injury & Frequency $(\mathrm{n}=396)$ & Percentage (\%) \\
\hline Head \& neck & 302 & 76.25 \\
Abdominal & 107 & 27.02 \\
Chest & 63 & 15.90 \\
Spine & 7 & 1.77 \\
Musculoskeletal & 78 & 19.70 \\
Pelvis & 5 & 1.26 \\
\hline
\end{tabular}

Table 4. Length of stay among trauma patients in the ICU.

\begin{tabular}{ccc}
\hline Length of stay (Days) & Frequency $(\mathrm{n}=396)$ & Percentage \\
\hline$<1$ & 63 & 15.91 \\
$1-7$ & 234 & 59.09 \\
$8-14$ & 55 & 13.89 \\
$15-21$ & 25 & 6.31 \\
$>21$ & 19 & 4.80
\end{tabular}

than 45 years was higher than the general mortality $(\mathrm{p}=0.03)$. Mortality was also higher in patients with LOS $\leq$ 7 days $(\mathrm{p}=0.00)$ (Table 5$)$.

\section{Discussion}

We discovered an ICU admission rate of $29.66 \%$ among trauma patients with a mean age of $29.9 \pm 16$ years. The most common causes of injuries were burn and road traffic accident and the median length of stay was 7 days.

Trauma admission rates in general ICUs from previous studies in our nation vary considerably with reports ranging from $20 \%$ to $68 \%$ [6]-[8]. It is known that location of health facilities as regards proximity to major motor ways usually influence the rate of trauma admissions in these facilities. This may among other factors account for the sharp differences in the rates of trauma admissions we see in our ICUs across the country. The male preponderance in our study like in most other studies is probably due to the fact that males are most likely to engage in high risk activities. Our trauma patients were also young. They were generally younger than patients in the study by Olajumoke et al. [7], and Adenekan \& Faponle [8] in Nigeria but comparable to the patients in the studies by Chalya et al. [9] in Tanzania. 


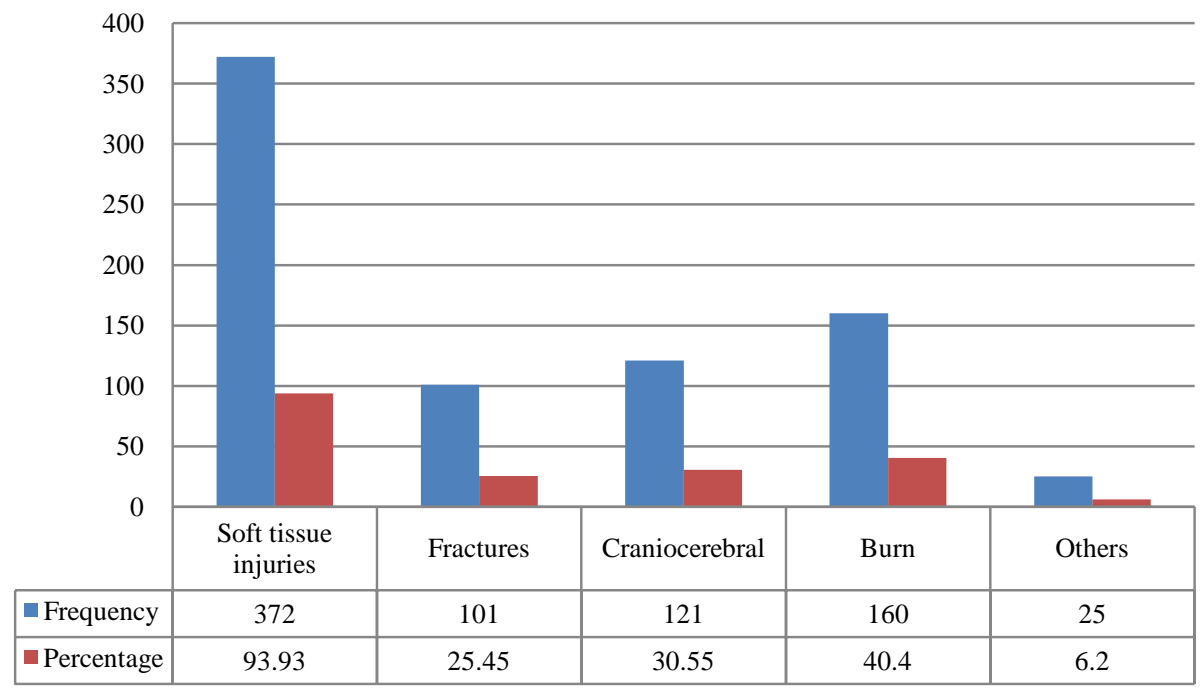

Figure 2. Types of injury.

Table 5. Variables of trauma patients admitted into the ICU indicating outcome mortality.

\begin{tabular}{|c|c|c|}
\hline \multirow{2}{*}{ Variable } & \multicolumn{2}{|c|}{ Outcome } \\
\hline & Survivor $(n=203)$ & Non-survivor $(\mathrm{n}=193)$ \\
\hline \multicolumn{3}{|l|}{ Sex $[n(\%)]$} \\
\hline Male & 159 (78.33) & $138(71.50)$ \\
\hline Female & $44(21.67)$ & $55(28.50)$ \\
\hline \multicolumn{3}{|l|}{ Diagnosis [n(\%)] } \\
\hline Burn & $62(30.54)$ & 98 (50.78) \\
\hline Head injury & 56 (27.59) & 65 (33.68) \\
\hline Abdominal trauma & 15 (7.39) & $4(2.07)$ \\
\hline Chest trauma & 18 (8.87) & $5(2.59)$ \\
\hline Polytrauma & 47 (23.15) & $19(9.84)$ \\
\hline Spine trauma & $5(2.46)$ & $2(1.04)$ \\
\hline \multicolumn{3}{|c|}{ Age ranges in years [n(\%)] } \\
\hline $0-1$ & $10(4.93)$ & $8(4.15)$ \\
\hline $2-15$ & 47 (23.15) & 31 (16.06) \\
\hline $16-30$ & $76(37.44)$ & $98(50.78)^{*}$ \\
\hline $31-45$ & 44 (21.67) & 29 (15.03) \\
\hline$>45$ & $26(12.81)$ & $27(13.99)^{*}$ \\
\hline \multicolumn{3}{|l|}{ LOS in days $[n(\%)]$} \\
\hline $0-7$ & $130(64.04)$ & $167(86.53)^{*}$ \\
\hline $8-14$ & $34(16.75)$ & $21(10.88)$ \\
\hline$\geq 15$ & 39 (19.21) & $5(2.59)$ \\
\hline
\end{tabular}

Key ${ }^{*}=\mathrm{p}<0.05$, LOS $=$ Length of stay. 
Unlike other studies from Nigeria within the same period which had most of their trauma admissions in the ICU being due to road traffic accident [6]-[8], majority of our trauma ICU admissions were due to burn. This though may not be a reflection of the proportion of trauma patients in the hospital generally because only the severe cases are admitted into the ICU. Majority of the burn cases in our series resulted from poor handling of petroleum products, some of the products were adulterated. A lot of people were storing petroleum products in residential places due to scarcity that was recurring and many of the victims were also dealers in the products in the black market who sold the products in jerry cans and gallons and also stored them in their residence. A previous study from the same centre on burn patients in the ICU made a similar observation with this study on the most common cause of burns [10]. Since the hospital did not have a burns unit most patients who could not be managed in the ward were admitted into the ICU. Like in findings from other ICUs in the country [6]-[8], and in other parts of Africa and the world road traffic accidents (RTAs) was a major cause of injury among our patients [9] [13]. Also like in previous studies from the same centre [11] [12] and from another study from Tanzania [9] and in parts of Asia [14], a high proportion of the RTAs were due to motorcycle crashes. Following the outlawing of motorcycles as a means of public transport in some parts of the state some years ago this pattern may have changed but RTAs still constitute a major reason for trauma admissions into our ICU.

Head injury was the most common reason for admission resulting from RTA. This was similar to findings from within and outside our region [7]-[9] [13]. The failure of authorities concerned to enforce the use of crash helmets by motorcycle riders is probably a factor in the high number of head injuries seen in our series and those from other developing nations. It must be said that this pattern of trauma admission in the ICU does not necessarily represent the general population of trauma patients in the hospital since only the severely injured were admitted into the ICU. Indeed previous studies involving trauma patients in our centre and from other hospitals in our region have found lacerations and fractures of the limbs as the most common forms of injuries presenting at the emergency departments [11] [15]-[18].

Mortality in our study was lower than that found in some ICUs in our country [8], but higher than reports from other ICUs within Africa and other parts of the world [9] [19] [20]. The high level of mortality in our study could be attributed to the low level of facilities and qualified personnel in our ICU. At the time of this study our ICU had only one ventilator which meant that some patients who required mechanical ventilation were denied this service. This inadequacy was also true for many other facilities both diagnostic and therapeutic in the ICU. Since injury scores were not generally applied in our patients we were not able to compare the severity of injury in our patients with patients in other ICUs. Mortality among trauma patients was higher than the overall mortality among ICU patients during the period. There is no dedicated trauma ICU in Jos University Teaching Hospital and as such all critically ill trauma patients are cared for in the general ICU. It is still debatable whether trauma patients do better in trauma ICUs compared to general ICUs. The study by Duane et al. [20] suggests that severely injured patients do better when managed in trauma ICUs. The study also stressed the importance of qualified, experienced personnel above location in the less severely injured patients.

Most of our patients had a length of stay (LOS) of 7 days and below and in agreement with other studies, survivors had a longer LOS [7]-[9]. A possible reason why many of our patients died early was due to lack of pre-hospital care and ambulance services. Often victims were transported to hospitals under suboptimal conditions and resuscitation and care only started when they arrived alive in the hospital thereby losing precious time.

Our study found a bimodal pattern of deaths with regards to age. The high mortality within the age range 16 30 years may be attributed to the severity of injury among this group while the high mortality that occurred after 45 years may be due to the high level of co-morbidity in this age group.

\section{Limitations}

There are several scoring systems applied in trauma patients which could predict outcome in these patients. They were not applied in our patients except for Glasgow coma scale in patients with head injury. Their application would have given us the opportunity to compare predicted outcomes with observed outcomes. Also being a retrospective study some missing data precluded some patients from being part of the analysis for this study.

\section{Conclusion}

Trauma constitutes a significant cause of admissions into the general ICU and mortality in these patients is much higher than in the general population of ICU patients. Improved pre-hospital care and ambulance services would 
ensure the victims arrive hospitals earlier and in better conditions while better facilities in the hospitals and ICUs would ensure better in-hospital care. Establishing trauma ICUs would lead to stream lining of facilities which could improve outcome.

\section{References}

[1] Schmucker, U., Steifert, J., Stengel, D., Matthes, G., Ottersbach, C. and Ekkemkamp, A. (2010) Road Traffic Crashes in Developing Countries. Unfallchirurg, 113, 373-377. http://dx.doi.org/10.1007/s00113-010-1777-9

[2] WHO (2013) Road Traffic Deaths Data by Country. Global Health Observatory Data Repository. http://apps.who.int/gho/data/node.main.A997

[3] Amez, P.C. and Linn, J.F. (2010) An Agenda for Research on Urbanization in Developing Countries: A Summary of Findings from a Scoping Exercise. The World Bank, Geneva.

[4] Murray, C.J.L. and Lopez, A.D. (2013) Measuring the Global Burden of Disease. New England Journal of Medicine, 369, 448-457.

[5] World Health Organization Ebola Response Team (2014) Ebola Virus Disease in West Africa—The First 9 Months of Epidemic and Forward Projections. New England Journal of Medicine, 371, 1481-1495.

[6] Amanor-Boadu, S.D., Sanusi, A.A., Oyeleke, S.O. and Soyanwo, O.A. (2003) Intensive Care for Trauma Victims in a Developing Country: Priorities and Challenges for Improvement. African Journal of Trauma, 1, 51-53.

[7] Olajumoke, T.O., Oyebamiji, E.O., Afolayan, J.M. and Adekunle, M. (2014) Trauma Admissions into the Intensive Care Unit and Outcome of Care in a Tertiary Health Facility. Nigerian Journal of Medicine, 23, 296-301.

[8] Adenekan, A.T. and Faponle, A.F. (2009) Trauma Admissions to the ICU of a Tertiary Hospital in a Low Resource Setting. African Journal of Anaesthesia and Intensive Care, 9, 5-9.

[9] Chalya, P.L., Gilyoma, J.M., Dass, R.M., Mchembe, M.D., Matasha, M., Mabula, J.B., et al. (2011) Trauma Admissions to the Intensive Care Unit at a Reference Hospital in North Western Tanzania. Scandinavian Journal of Trauma, Resuscitation and Emergency Medicine, 19, 61. http://dx.doi.org/10.1186/1757-7241-19-61

[10] Yiltok, S.J., Isamade, E.S. and Uba, A.F. (2005) Outcome of Burn Patients Managed in a General Intensive Care Unit. Nigerian Journal of Surgery, 11, 1-4.

[11] Adoga, A.A. and Ozoilo, K.N. (2014) The Epidemiology and Type of Injuries Seen at the Accident and Emergency Unit of a Nigerian Referral Center. Journal of Emergencies, Trauma and Shock, 7, 77-82. http://dx.doi.org/10.4103/0974-2700.130875

[12] Nwadiaro, H.C., Ekwe, K.K., Akpayak, I.C. and Shitta, H. (2011) Motorcycle Injuries in North-Central Nigeria. Nigerian Journal of Clinical Practice, 14, 186-189. http://dx.doi.org/10.4103/1119-3077.84012

[13] Gardiner, J.P., Judson, J.A., Smith, G.S., Jackson, R. and Norton, R.N. (2000) A Decade a of Intensive Care Admissions in Auckland. New Zealand Medical Journal, 113, 327-330.

[14] Nantulya, V.M. and Reich, M.R. (2002) The Neglected Epidemic: Road Traffic Injuries in Developing Countries. BMJ, 324, 1139-1141. http://dx.doi.org/10.1136/bmj.324.7346.1139

[15] Solagberu, B.A., Adekanye, A.O., Ofoegbu, C.P.K., Karanga, S.A., Udoffa, U.S., Abdur-Rahman, L.O., et al. (2002) Clinical Spectrum of Trauma at a University Hospital in Nigeria. European Journal of Trauma, 28, 365-369. http://dx.doi.org/10.1007/s00068-002-1223-y

[16] Thanni, L.O.A. and Kehinde, O.A. (2006) Trauma at a Nigerian Teaching Hospital: Pattern and Documentation of Presentation. African Health Sciences, 6, 104-107.

[17] Elachi, I.C., Yongu, W.T., Odoyoh, O.D., Mue, D.D., Ogwuche, E.I. and Ahachi, C.N. (2015) An Epidemiological Study of the Burden of Trauma in Makurdi, Nigeria. International Journal of Critical Illness and Injury Science, 5, 99-102. http://dx.doi.org/10.4103/2229-5151.158404

[18] Chalya, P.L., Dass, R.M., Mchembe, M.D., Mbelange, N., Ngayomala, I.H., Chandika, A.B., et al. (2013) City Wide Trauma Experience in Mwanza, Tanzania: A Need for Urgent Intervention. Journal of Trauma Management \& Outcomes, 7, 9. http://dx.doi.org/10.1186/1752-2897-7-9

[19] Mitchell, V.T., Scarlet, M.D. and Amata, A.V. (2001) Trauma Admissions to the ICU of the University Hospital of the West Indies, Kingston, Jamaica. Trauma Care Fall/Winter, 86-89.

[20] Duane, T.M., Rao, I.R., Aboutanos, M.B., Wolfe, L.G. and Marlhortra, A.K. (2008) Are Trauma Patients Better off in a Trauma ICU? Journal of Emergencies, Trauma and Shock, 1, 74-77. http://dx.doi.org/10.4103/0974-2700.43183 
Submit or recommend next manuscript to OALib Journal and we will provide best service for you:

- Publication frequency: Monthly

- 9 subject areas of science, technology and medicine

- Fair and rigorous peer-review system

- Fast publication process

- Article promotion in various social networking sites (LinkedIn, Facebook, Twitter, etc.)

- Maximum dissemination of your research work

Submit Your Paper Online: Click Here to Submit

Contact Us: service@oalib.com 